\title{
Pilot project delivers dementia care that feels like home
}

\author{
n Cite as: CMAJ 2018 June 11;190:E729. doi: 10.1503/cmaj.109-5610
}

Posted on cmajnews.com on May 23, 2018.

$\mathrm{T}$ here's not much that's homey about long-term care for people with dementia. Usually, the environment is clinical, the staff are uniformed, and the day is structured. It's a place where antipsychotics and restraints may be used. It's not uncommon for residents to feel abandoned, their families to feel guilty, and staff to burn out. But a model of dementia care that emphasizes relationships over routine is transforming facilities across the country into friendlier spaces.

First developed in the United Kingdom in the 1990s, the Butterfly care model focuses on putting people before tasks and creating a homelike environment in dementia facilities that encourages social time between staff and residents. "It's about breaking down the 'us' and 'them' features so that team members working in the care home are like family and friends sharing the day with people," Catarina Versaevel, national director of Dementia Care Matters Canada, said at the Advancing Senior Care Conference in Toronto.

This includes "creating environments that are rich in color and filled with the stuff of life," such as magazines and puzzles. Residents have more freedom to do activities like tidying, dressing up and making snacks. They dine family-style with staff and can help themselves to seconds. Staff wear their own clothes instead of uniforms and engage with residents throughout the day, "not just at the time of structured activities."

Last year, Malton Village Long Term Care Centre in the Region of Peel became the seventh facility in Canada, and the first in Ontario, to adopt the model. Residents were separated into households of

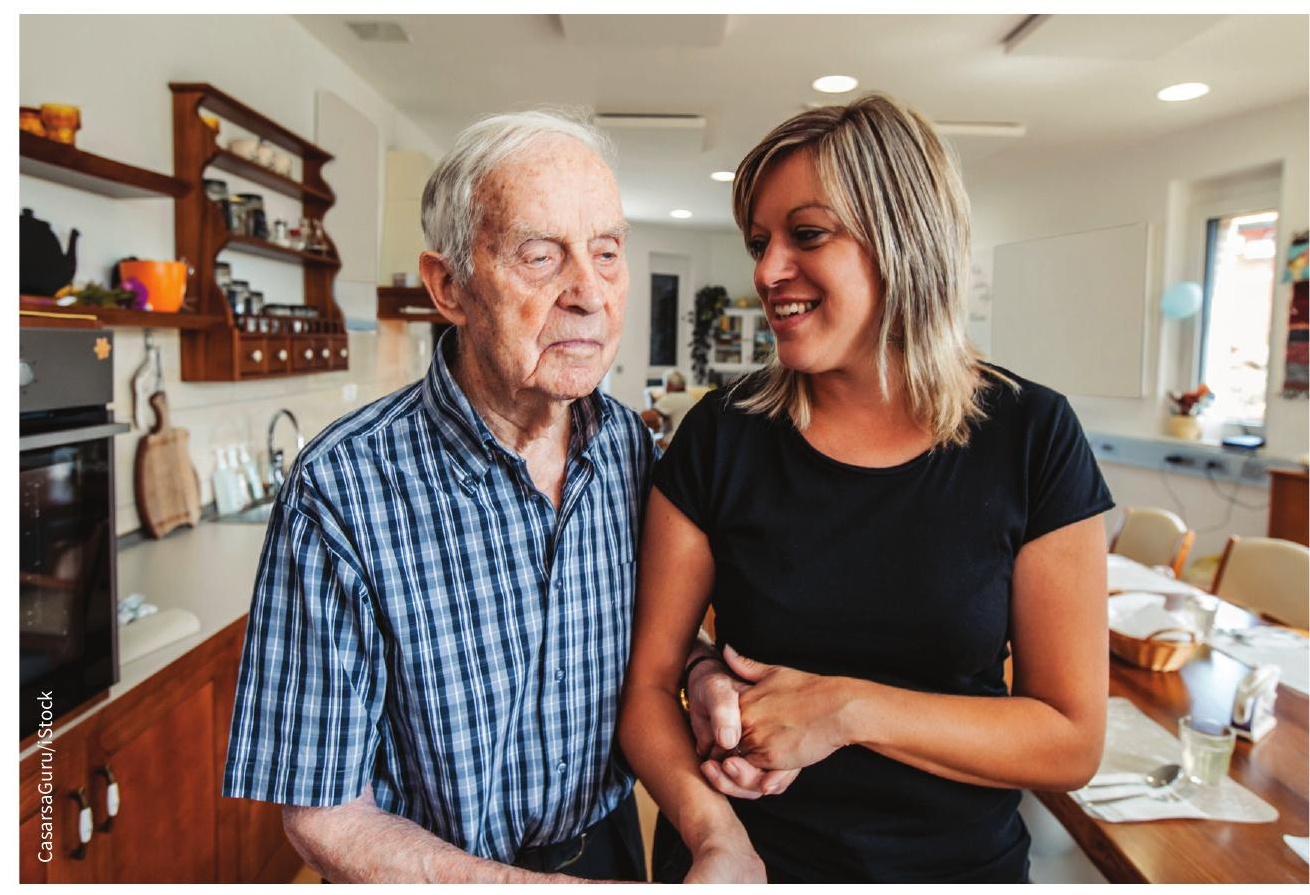

Making long-term care less institutional may improve outcomes for people with dementia.

10-12 people based on stage of dementia. People in earlier stages became more social when grouped together, and those in later stages became calmer.

Initially, staff were hesitant to let go of their uniforms and engage more personally with patients. "We've taught people over hundreds of years that to be professional, you maintain some distance, so asking people to share a little bit of themselves is difficult," explained Mary Connell, project manager for the Region of Peel.

Staff received eight days of training over four months to transition from "doing for to being with" residents. The model requires a higher ratio of staff to residents, although potentially less nursing staff, which may offset some costs. Butterfly homes in Australia call in registered nurses only when residents are sick.
Since adopting the model, Malton Village Long Term Care Centre has seen improvements in pain, unintended weight loss, responsive behaviours, social engagement, staff and family satisfaction, and there have been fewer falls and reduced usage of antipsychotics. The region plans to roll out the model to all five of its longterm care facilities over the next three years.

Butterfly homes in Alberta, the UK and Australia have reported similar results. In Edmonton, Lifestyle Options Retirement Communities saw behaviours like grabbing, screaming, pacing and cursing drop more than $90 \%$. Antipsychotic medication use decreased by $68 \%$ and employee sick time fell by $90 \%$.

Lauren Vogel, CMAJ 